\title{
The Moderating Effect Of Long-Term Orientation On The Relationship Between Interfirm Power Asymmetry And Interfirm Contracts: The Cases Of Korea And USA
}

Sungmin Ryu, Ph.D, Sungkyunkwan University, South Korea Eunjung Kim, Duksung Women's University, South Korea

\begin{abstract}
The purpose of this study is to enhance our understanding of the effects of LTO culture on the contractual relationship between exchange parties under conditions in which varying levels of asymmetrical power structures exist. This study attempt to determine the validity of projecting conclusions originating from studies conducted in low LTO cultures such as U.S. and Western Europe to contractual relationships in the high LTO cultures of Asia. Therefore, investigations into the influence of LTO may be helpful in understanding contractual relationships formed in countries with differing levels of long-term orientation. Survey research was conducted to collect data from manufacturers, Structural Equation Modeling was used to purify measurement scales, and Multiple Regression was conducted to test the hypotheses. The findings show that LTO companies tend to prefer "soft" contracts, although they enjoy a power advantage over their suppliers; whereas low LTO partners with asymmetrical power advantages prefer "hard" contracts with explicitly detailed written requirements.
\end{abstract}

Keywords: Cross-national buyer-seller relationship, Long-term orientation culture, Contracts

\section{INTRODUCTION}

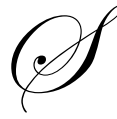

tudies regarding contractual relationships between exchange parties have improved our understanding of interfirm governance mechanisms. Scholars have identified crucial factors that affect contractual relationships: studies have shown that interfirm characteristics including environmental uncertainty (Cannon, Achrol, and Gundlach 2000), relationalism (Antia and Frazier 2001), purchasing volume (Buvik and Reve 2001), transaction specific investment (Antia and Frazier 2001; Buvik and Reve 2001;Cannon, Achrol, and Gundlach 2000), interdependence magnitude (Antia and Frazier 2001, Lusch and Brown 1996), and interdependence asymmetry (Antia and Frazier 2001) affect the manner in which contractual relationships develop and how successful these relationships are.

Although the influence of these micro factors on relationship quality between exchange parties has been investigated extensively, the influence of culture has yet to be scrutinized with the same thoroughness. Indeed, comparative studies designed to evaluate the influence of culture on exchange parties' behavior in different cultures has been fairly rare (Chang \& Ding 1995). This limits the confidence with which one may generalize relationship characteristics when exchange parties from dissimilar cultures are studied (Eng 2009; Zhao and Cavusgil 2006; Doney \& Cannon 1997). As the global economy expands, exchange partners from the East and West interact with increasing frequency. Certainly, East-Asian countries can be expected to exhibit corporate relationships that mirror their socio-cultural orientation, just as Western transactions tend to be reflective of cultural patterns. The present study attempts to provide a greater understanding of cultural influences in interfirm relationships, via the examination of contractual buyer-seller relationships between Korean and U.S. manufacturers and their suppliers. 
Among the cultural dimensions developed by researchers, long-term orientation (LTO) has been recognized as a key factor in explaining social interactions (e.g., Polo-Redondo and Cambra-Fierro 2008; Barkema \& Vermeulen 1997; Newman and Nollen 1996; Hofstede 1991). Hofstede's fifth dimension of national culture (Hofstede 1991), also referred to as LTO, is the extent to which a society exhibits a pragmatic future-oriented perspective rather than a conventional short-term point of view (Mooij 1997). Corporate relationships in LTO cultures, once established, tend to endure over long periods of time. Thus, parties to these relationships tend to handle current issues in the context of long-term goals, rather than short-term gains or problems, in mind. By way of contrast, exchange parties in low LTO cultures tend to engage in comparatively short-term relationships and, in turn, to expect channel relationships to be relatively short-lived as well. Many industrialized Western countries fall into this category.

The principal objective of this study was to enhance our understanding of the effects of LTO culture on the contractual relationship between exchange parties under conditions in which varying levels of asymmetrical power structures exist. Although LTO cultures have been confirmed at international levels (Nakata \& Sivakumar 1996, Chang \& Ding 1995, Yeh \& Lawrence 1995) and this quality has been accepted as an important one for describing differences among nations (Newman \& Nollen 1996), there has been no empirical research conducted thus far on the effects of LTO on interfirm contractual relationships. Specifically, we have assessed the moderating effects of LTO on the relationship between interfirm power asymmetry and contractual relationships. We attempted to determine the validity of projecting conclusions originating from studies conducted in low LTO cultures such as U.S. and Western Europe to contractual relationships in the high LTO cultures of Asia. Therefore, investigations into the influence of LTO may be helpful in understanding contractual relationships formed in countries with differing levels of long-term orientation.

In the next section, we provide the theoretical framework upon which our propositions were based. We identify the dimensions of LTO culture relevant to corporate contractual relationships. Hypothetical relationships are proposed on the basis of LTO strength. Subsequently, the research design and data analysis are presented. Finally, the research results are analyzed for theoretical implications, and the study limitations are discussed.

\section{THEORETICAL BACKGROUND AND HYPOTHESES}

Interfirm relationships are influenced by the cultural milieu of individual exchange partners. East Asian countries including Korea, Japan, and China tend to understand all social interactions as long-term. Their social and business relationships are maintained and reinforced via continuous and long-term associations (Yeung \& Tung, 1996). Both current problems and advantages are generally viewed within the context of outcomes anticipated in the distant future. These countries foster virtues oriented toward future rewards (as opposed to short-term gain) and this orientation is expressed as a high score on the LTO index (Hofstede 1991). Discrete transactions are, for Asians, generally viewed as a component of the larger, more important whole of the on-going relationship.

In the West, by contrast, social transactions of all types are more frequently recognized as isolated occurrences. The primary objective of any transaction is to achieve optimal "give and take" in that particular transaction. Emphasis is placed on the immediate gains from the interaction (Yeung \& Tung, 1996). Countries in which citizens evidence these transaction-focused tendencies (including the USA, the UK, and Canada) score relatively low on the LTO index (Hofstede 1991).

LTO cultures are characterized by a high level of perseverance (Hofstede 1991). Perseverance is a consistent and determined effort toward the achievement of goals (Hofstede 1991). Goals are future positions an exchange party wishes to attain, and goals exist only if the desired position differs from the actual state (Cadotte \& Stern 1979). In cases in which the exchange party regards its goals as being difficult to achieve, persistence is necessary, as attainment cannot be imminent. Persistence focuses on the long-term for payoffs for current efforts. Thus, perseverance involves a high level of long-term orientation. East Asian countries score high on the value of perseverance (Hofstede 1991). Rokeach's Value Survey (Rokeach 1973) did not find a high value being placed on perseverance in the US. This implies that Western countries tend to possess a lower level of perseverance than East Asian countries, and also lends further support to the notion that perseverance and LTO are associated. 


\section{Interdependence Asymmetry}

Interdependence asymmetry between exchange parties refers to one party's relative power over the other party in an exchange, which in turn influences the stronger party's deterrence ability over its partner. Deterrence is defined as one party's threat to employ power to prevent its partner from employing power (Morgan 1977). Thus, deterrence involves a party's restriction of its partner's behavior by threatening it with harm.

According to the theory of bilateral deterrence (Bacharach and Lawler 1981), interdependence asymmetry results in a greater use of power by the more powerful party than does interdependence symmetry. Given a constant degree of interdependence magnitude, the less powerful party possesses insufficient power to deter its powerful partner, and thus the more powerful party can apply its power for its interest only. Thus, the more powerful party does not need to consider the less powerful party, and can always use its relative power to acquire its partner's compliance (Kumar, Scheer, and Steenkamp 1995). Therefore, exchange parties that enjoy a relationship of interdependence asymmetry with their partners are involved in a relationship that is characterized by less cooperation and greater conflict (Dwyer, Schurr, and Oh 1987).

\section{Contracts}

Contracts refer to the promise between exchange parties to project exchanges into the future (Macneil 1980). Thus, contracts shape or attempt to shape relationships in the future, and they would not exist without some expectation of future dealings. As exchange parties cannot perfectly predict the future, the content of a contract may not adequently reflect future contingencies. Therefore, either party may be vulnerable to the other if one attempts to take advantage of unclear or missing contract terms. In their explicit protection against possible opportunistic behaviors, scholars have divided contracts into two categories: soft contracts and hard contracts.

A soft contract refers to the existence of implicit, mutual understanding of expected roles and behaviors on the part of the exchange parties (Smith, Carroll, \& Ashford 1995). As soft contracts rely on unstated understanding, the soft contract does not establish specific stipulations. Exchange parties that rely on soft contracts establish expectations regarding outputs and behavior standards as a foundation for their ongoing interactions. Such an expectation of outputs and behavior standards are not necessarily legally binding; rather, both exchange party's beliefs about salient relationship issues in the interactions among themselves (John 1984).

The soft contract is an incomplete contract, as large portions of them are unwritten and exist principally in the understanding of the agreeing parties. Incomplete contracts are necessary when exchange parties are unable to obtain complete information regarding the situation with which they are dealing. This incompleteness involves the extent to which the explicit, formal terms are left open for possible modification through subsequent negotiations (Ghosh and John 2000). Incomplete contracts permit exchange parties to save costs, such as the costs associated with searching for information on future contingencies or the costs inherent to the writing of fully contingent contracts (Klein 2002).

Soft contracts are useful in cases in which the performance of exchange parties is difficult to measure. For instance, a supplier's responsiveness to a customer's urgent request for extra parts cannot be readily measured. There are several contingencies involved in the responsiveness to urgent requests, such as the extent of parts stocks, the delivery time allowed the supplier, the price of the parts, etc. Thus, it is not feasible, nor is it generally possible, for exchange parties to specify all contingencies in terms of measuring the supplier's performance. Thus, incomplete contracts may leave the parties vulnerable to opportunistic behavior, as they make it possible to exploit unstated or vague contractual terms. Thus, incomplete contracts lower incentives to make investments, as they permit greater opportunities for appropriation (Ghosh and John 2000).

According to bilateral deterrence theory (Bacharach and Lawler 1981), interdependence asymmetry results in a greater use of power by the more powerful party to a contract. The less powerful party is unable to deter its powerful partner from using its power only for its interests. Thus, the more powerful party does not need to consider the less powerful party, and can always use its relative power to acquire its partner's compliance (Kumar, Scheer, and Steenkamp 1995). Therefore, the exchange relationship of interdependence asymmetry is characterized by 
greater conflict (Kumar et al. 1995). As a soft contract is predicated on mutual understanding between exchange parties, the conflict prohibits the parties from developing soft contracts. As interdependence asymmetry increases, exchange parties are less willing to rely on soft contracts.

H1: There is a negative relationship between power asymmetry and soft contracts.

Exchange parties whose relationship has a long-term orientation accept short-term disadvantages, as these may be expected to be balanced out by longer-term advantages (Noordewier, John, and Nevin 1990). Thus, exchange parties in LTO cultures are less likely to engage in short-term self-interested behavior. Instead, they are more likely to pursue benefits accruing from future relationships, and thus they seek to continue the positive relationship with their partners. Through continued relationships, exchange parties enjoy a better chance of developing mutual understanding. Therefore, exchange partners with long-term cultures moderate the negative effects of interdependence asymmetry on soft contracts.

H2: As the cultural influence of LTO increases, the relationship between power asymmetry and soft contracts becomes positive.

A hard contract refers to detailed contractual agreements which specify at length the roles and obligations of the parties (Cannon, Achrol, \& Gundlach 2000; Smith, Carroll, \& Ashford 1995). A hard contract generally spells out detailed contractual obligations, and specific rules and regulations, as well as detailed penalties for failures to perform designated tasks.

Hard contracts contain the notion of legitimacy, which forces exchange parties to observe the terms of the contract. Exchange parties with hard contracts are, therefore, constrained to behave in certain ways, as formalized by the written contract. Thus, hard contracts constitute a formal governance mechanism in the exchange relationship (Uzzi 1999).

Hard contracts are necessary in cases in which renegotiation between exchange parties is not necessary (Seshadri and Mishra 2004). For example, a manufacturer that forces parts suppliers to drop the price of their supplied parts by a certain percentage should not allow for any renegotiation on the parts price. Otherwise, it is meaningless to establish detailed contracts in order to achieve the goal of obtaining low-priced parts.

An exchange party that has interdependence asymmetry with its partner is involved in a relationship which tends to be characterized by less cooperation and more conflict (Dwyer, Schurr, and Oh 1987). Elaborate contracts may function as a form of quasi-integration, and thus they may be used for adaptation to uncertain environments and safeguarding the property from opportunistic partners (Stinchcombe 1985). The party with the less cooperative partner, therefore, attempts to obtain an explicit contract in an effort to force its partner to observe the terms of the contract. As power asymmetry increases, the exchange party is more likely to rely on hard contracts.

H3: There is a positive relationship between power asymmetry and a hard contract.

Exchange parties with long-term perspectives anticipate that their relationships will continue over a long period of time, and will accrue longer-term benefits. Therefore, they tend to avoid dishonesty and opportunistic behavior which might jeopardize a relationship, not for contractual reasons but for the sake of future profits. The continuity of a partnership is regarded as the source of a mutual long-term pay-off. Thus, as the influence of LTO culture increases, the positive relationship between power asymmetry and a hard contract is weakened.

Exchange parties in low LTO cultures assume short-term relationships with their contractual partners. They tend to utilize detailed hard contracts, which work best when covering current or near-future situations, as time increasingly brings changed conditions and unforeseen events. Thus, a very specific hard contract would be most effective in prohibiting opportunistic behavior in a relatively short-term culture. However, as time orientation becomes longer-term, the contractual parties anticipate that relationships will continue and accrue benefits over a longer period of time, thus reducing the benefits of a hard contract. Therefore, we suggest the following: 
H4: As the cultural influence of LTO increases, the relationship between power asymmetry and a hard contract becomes negative.

Figure 1: Conceptual Framework

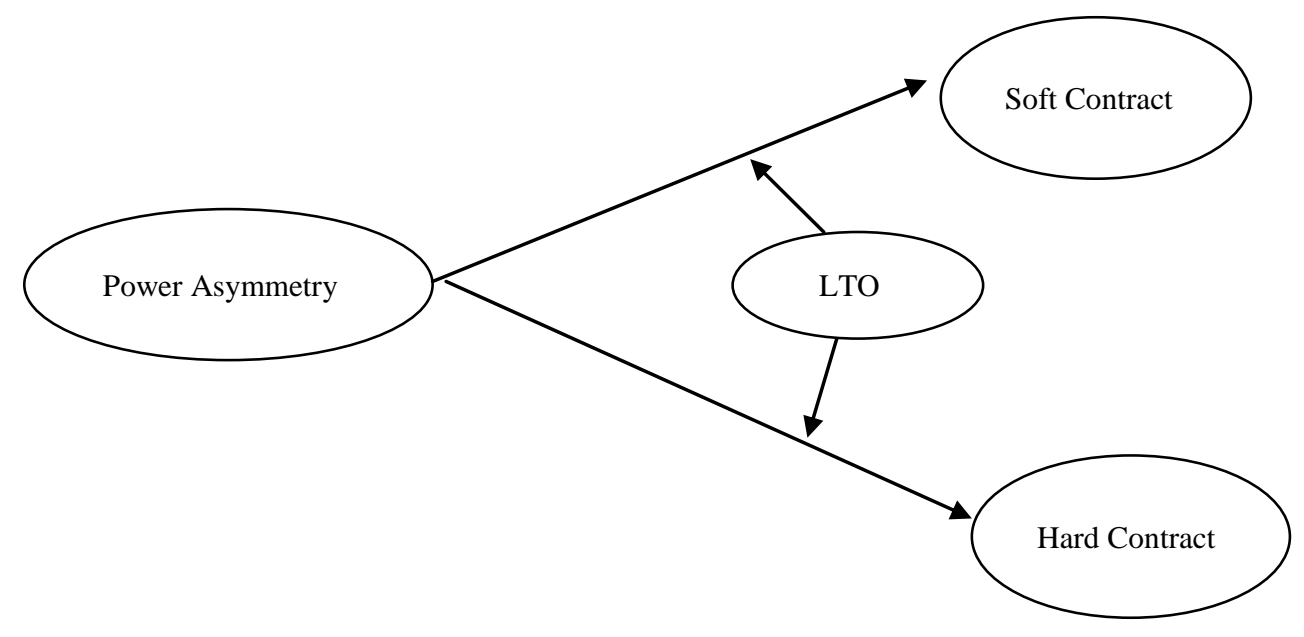

\section{RESEARCH DESIGN}

In order to test our hypotheses, we assessed purchasing relationships between manufacturers and their suppliers in both Korea and the U.S. These two countries were selected for two reasons. First, according to Hofstede (1991), the two countries represent polar opposites in time orientation, with Korea ranking among the highest on his LTO cultures scale, whereas the U.S. is a well-known representative short-term perspective country (Jacobs 1991). Second, even though Korea has been developing rapidly over the past 30 years, research into international corporate relationships with Korea remains rare, and we hoped to make a contribution to our understanding of Korea as an international contract partner.

\section{Sample}

We initially selected 680 U.S. manufacturing firms (SIC codes from 3011 to 3999) from the Dunn and Bradstreet directory. Manufacturers in Korea were selected as a systematic random sample of 502 firms from a mailing list of the Korean Manufacturers Association. The sample of respondents was drawn from a variety of industries in order to improve the generalizability of the results by minimizing the effects of industry-specific characteristics.

Each respondent was mailed a questionnaire and instructed to complete it with regard to a major supplier. After callbacks and a second mailing, 105 (Korea) and 130 (U.S.) surveys were collected, yielding response rates of approximately $21 \%$ (Korea) and $19 \%$ (U.S.).

The usable responses were tested for nonresponse bias by comparing early respondents with late respondents (Armstrong and Overton 1977). The mean value for each scale (i.e., long-term orientation, soft contract, and hard contract), and the characteristics of the participating companies and the key informants (i.e., years of relationship with the supplier, years of experiences of the respondents as purchasing managers) were compared across the two groups. The comparison results evidenced no sign of significant differences between the two groups (the p-values for the comparisons ranged from .24 to .31 for Korea data and between 25 and 36 for US data). Additionally, the responding firms were compared with the nonresponding firms on the basis of characteristics such as the numbers of employees and total sales, using the secondary data acquired from Corporate Affiliations Plus (2000) for US data, and from the Korean Commercial and Manufacturing Association for Korean data. The 
comparison results generated no significant differences. Finally, the response rates across the different industries in the sample (i.e., electronics, metal, textile, and steel) revealed no significant differences (i.e., $\mathrm{p}<.61$ for Korean data and $\mathrm{p}<.60$ for US data), thereby suggesting that the data were not skewed by non-response bias.

\section{Measurement Scale Development}

The Korean version of the questionnaire was translated by the first author, whose native language is Korean, and subsequently back-translated by a bilingual Korean-English colleague.

Scale development measurement was conducted in two stages. First, the existing measures of the focal variables were collected from the relevant literature. Then, in-depth interviews were conducted with three purchasing managers in order to evaluate the relevance of the collected measures. The wordings of some of the items were revised on the basis of the inputs from the purchasing managers. All items were assessed on 7-point Likert-type scales anchored by 1 (strongly disagree) and 7 (strongly agree) as endpoints.

LTO culture. This scale captures the exchange parties' perception of their countries' levels of long-term orientation. This LTO scale was not developed in the inter-organizational literature. Thus, on the basis of Hofstede's (1991) original wording, each item was adapted by the first author for use in the present context.

Power asymmetry: In order to compute the variables of interdependence asymmetry, we measured the supplier's dependence on the manufacturer and the manufacturer's dependence on the supplier, as perceived by the manufacturer (see Table 1). Interdependence asymmetry (favoring the manufacturer) was calculated by subtracting the supplier's dependence from its buyer's dependence (Kumar, Scheer, and Steenkamp 1995). Thus, interdependence asymmetry reflects power in favor of the manufacturer (Jap and Ganesan 2000). The supplier's dependence on the manufacturer was measured via the same four items, as perceived by the manufacturer.

Contracts: Contract type was measured such that hard and soft contracts could be distinguished. Hard contracts were characterized by explicit, precise descriptions of each party's role, responsibilities, legal remedies for performance failures, and the method of conflict resolution. Soft contracts were characterized more by a reliance on mutual understanding (as opposed to contract stipulations) of each party's role, responsibilities, remedies for performance failures, and the method of conflict resolution. These items were utilized by Lusch \& Brown (1996).

\section{Construct Validity}

Each latent variable - Long-Term Orientation (LTO), Soft Contract (SOFTC), Hard Contract (HARDC), Manufacturer Dependence (MFRDEP), and Supplier Dependence (SUPDEP) - that was measured with multiple items was subjected to scale purification. On the basis of the item-to-total correlations, the ill-fitted items were dropped. The subsequent reduced sets of items were subjected to confirmatory factor analysis (CFA) using LISREL. Finally, the coefficient alpha for each construct was measured for reliability tests.

Following the scale purification process, a measurement model with acceptable fit indices was identified (Korea: $\chi^{2}(94)=110.40(\mathrm{p}=.12)$, GFI $=.92$ AGFI $=0.90$, CFI $=.94$, RMSEA $=.041$, US: $\chi^{2}(94)=105.41(p=.19)$, $\mathrm{GFI}=.91 \mathrm{AGFI}=0.89, \mathrm{CFI}=.93, \mathrm{RMSEA}=.035)$. All the factor loadings were found to be highly significant $(\mathrm{p}<$ .01 ), showing evidence of the convergent validity and the unidimensionality of the measures (Anderson and Gerbing 1988).

The discriminant validity of all 5 of the latent variables was assessed via $\chi^{2}$ Difference Tests: all the constructs in pairs (10 tests altogether) were tested if the restricted model (in which the correlation was fixed as one) was significantly worse than the freely estimated model (in which the correlated was freely estimated). All the $\chi^{2}$ differences were highly significant, evidencing discriminant validity (Anderson and Gerbing 1988). For example, the comparison regarding the soft contract and hard contract yielded a $\chi^{2}(1)=22.57(\mathrm{p}<.01)$ for US data, and $\chi^{2}(1)$ $=25.52(\mathrm{p}<.01)$ for the Korean data, thereby suggesting that these two constructs are distinct. 
Finally, the reliability coefficient of the construct was measured (between .63 and .83 for US, between 0.71 and 0.82 for Korea). Each factor evidences a satisfactory level of reliability. Collectively, these results indicate that the measures in this study had adequate reliability and validity. The factor loadings, reliability measures of each construct, and goodness-of-fit indices are reported in Table 1.

Table 1

Measurement Items and Validity

Korea: $\chi^{2}(94)=110.40(\mathrm{p}=.12), \mathrm{GFI}=.92 \mathrm{AGFI}=0.90, \mathrm{CFI}=.94, \mathrm{RMSEA}=.041$, US: $\chi^{2}(94)=105.41(p=.19)$, GFI $=.91$ AGFI $=0.89$, CFI $=.93$, RMSEA $=.035$

Long-Term Orientation Culture

CR: .71 (Korea), .73 (US)

Korea

SFL

In our country, members in a company

1. Working toward long-term organizational goal

2. Working for future relationship with exchange partner

$.58 \quad .57$

3. Saving company resources for future contingencies

$.81 \quad .74$

4. The importance of future relationship quality with exchange partner

5. The importance of current relationship quality with exchange partner (R)

$.45 \quad .50$

$.53 \quad .52$

Manufacturer dependence

$\mathrm{CR}=.75$ (Korea), .72 (US)

1. Difficult to replace major supplier's products with another supplier's $*$ product line.

2. The total costs of switching to a comparable supplier

3. Dependence on major supplier.

.60

.82

.64

.68

Supplier dependence:

$\mathrm{CR}=.78$ (Korea), .80 (US)

1. Supplier's difficulty to replace the sales and profits realized from your firm.

2. Major supplier's total costs of switching to another comparable customer.

3. Major supplier's dependence on your company.

$.59 \quad .78$

$.80 \quad .79$

$.61 \quad .57$

Soft Contract $\quad$ CR: .82 (Korea), .83 (US)

$\begin{array}{lll}\text { 1. Mutual understanding of the roles and responsibility } & .53 & .59\end{array}$

2. Mutual understanding of the behavior in case of unplanned event $r$\begin{tabular}{lr}
.52 \\
\hline
\end{tabular}

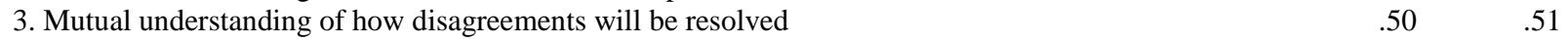

Hard Contract (HCONT) CR: .79 (Korea), .79 (US)

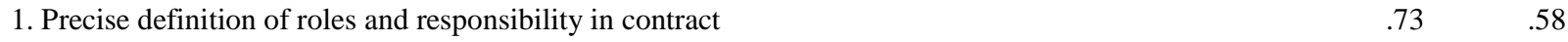

2. Detailed direction in contract about behavior for unplanned event $r \begin{array}{lr}.73 \\ .81\end{array}$

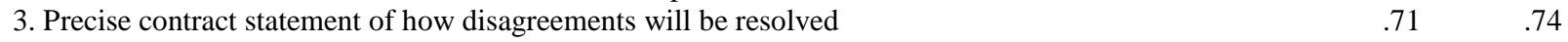

Note: * Items deleted from further analysis due to low factor loadings or high cross-loadings. $\mathrm{SFL}=$ Standardized Factor Loading, $\mathrm{CR}=$ Composite Reliability.

\section{Control Variables}

We included firm size and relationship length as control variables. Firm size was indicated by the logarithm of the number of employees. Relationship length was assessed by the number of years that the manufacturer has been doing business with the supplier. 
Table 2

Means, Standard Deviations, and Correlations

\begin{tabular}{|c|c|c|c|c|c|c|c|c|}
\hline \multicolumn{2}{|l|}{ 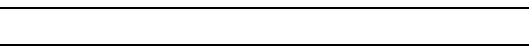 } & 1 & 2 & 3 & 4 & 5 & 6 & 7 \\
\hline \multicolumn{2}{|l|}{ 1. LTO (LTO) } & 1.00 & .17 & .02 & -.04 & -.16 & -.06 & -.14 \\
\hline \multicolumn{2}{|c|}{ 2. Soft Contract (SCONT) } & .33 & 1.00 & .13 & .03 & .01 & -.02 & .01 \\
\hline \multicolumn{2}{|c|}{ 3. Hard Contract (HCONT) } & .00 & .27 & 1.00 & -.01 & .16 & -.01 & -.07 \\
\hline \multicolumn{2}{|c|}{ 4. Manufacturer Dependence(MFRDEP) } & .05 & .21 & .04 & 1.00 & .23 & .03 & .02 \\
\hline \multicolumn{2}{|c|}{ 5. Supplier Dependence (SUPDEP) } & -.01 & .20 & .09 & .59 & 1.00 & .04 & -.04 \\
\hline \multicolumn{2}{|c|}{ 6. Company Size (SIZE) } & -.12 & -.05 & -.03 & .04 & .05 & 1.00 & .09 \\
\hline \multicolumn{2}{|c|}{ 7. Relationship Length (LENGTH) } & .08 & .14 & -.03 & .23 & .17 & .02 & 1.00 \\
\hline \multirow[t]{2}{*}{ Mean } & Korea & 5.68 & 5.35 & 4.72 & 3.88 & 4.07 & 4.43 & 12.24 \\
\hline & US & 4.25 & 5.26 & 4.08 & 3.60 & 3.89 & 4.12 & 15.54 \\
\hline \multirow[t]{2}{*}{ Standard Deviation } & Korea & .70 & .70 & 1.24 & 1.16 & 1.06 & 1.46 & 9.32 \\
\hline & US & .82 & .98 & 1.13 & 1.20 & 1.17 & 1.65 & 12.10 \\
\hline
\end{tabular}

Notes: The lower triangular matrix provides the correlations for Korea data, and the upper triangular matrix indicates the correlations for US data.

\section{ANALYSIS AND RESULTS}

Table 2 records the difference of long-term orientation cultures between Korea and the U.S.A. As had been expected, exchange parties in Korea evidence higher LTO than do exchange parties in the U.S.A. This is consistent across all items. Thus, table 2 supports the contention that Korea is a LTO culture, whereas U.S.A. is a low LTO culture. This result is consistent with the current literature, in which Asian countries are presented as having longterm orientations, whereas Western countries tend to have short-term orientations (Hofstede, 1991).

\section{Tests of Hypotheses}

The hypotheses were formally tested via multiple regression. Two tests were conducted to verify the hypotheses. The first test assessed hypotheses $1 \& 2$. The dependent variable in the regression model was the soft contract (SOFTC). The independent variables included the time-orientation of the culture (LTO), power asymmetry (POWASYM), the interaction variable of LTO and power asymmetry (LTO - POWASYM), and the control variables of relationship length (LENGTH) and firm size (SIZE). The equation was structured as follows:

$\mathrm{SOFTC}=b 0+b 1 \mathrm{LTO}+b 2$ POWASYM $+b 3 \mathrm{LTO} \cdot$ POWASYM +

Where

$$
b 4 \mathrm{LENGTH}+b 5 \text { SIZE }+u i
$$

$b 1, b 2, b 3, b 4, b 5=$ coefficient

$u i=$ an error term

The second test was for hypothesis 3 and 4 . The dependent variable in the regression model was the hard contract (HARDC), and the same independent variables utilized in the first two tests were included. The results are provided in Table 3.

Table 3

Regression Analysis for Hypothesis

\begin{tabular}{lcc}
\hline Independent Variables & \multicolumn{2}{c}{ Dependent Variables } \\
\hline LTO & SOFTC & HARDC \\
POWASYM & $.314^{\mathrm{b}}$ & -.024 \\
LTO $\cdot$ POWASYM & -.009 & $.224^{\mathrm{a}}$ \\
SIZE & $.213^{\mathrm{a}}$ & -.056 \\
LENGTH & -.034 & -.010 \\
\hline Adj. $\mathrm{R}^{2}$ & .104 & -.026 \\
\hline
\end{tabular}

$\mathrm{a}:$ reject Ho at $\mathrm{p}<.05$ (1-tailed test.)

$\mathrm{b}:$ reject Ho at $\mathrm{p}<.01$ (1-tailed test.) 
The results in Table 3 demonstrate that power asymmetry is not associated negatively with soft contracts. Although the theoretical rationale for the relationship between power asymmetry and soft contract is strong, this relationship is not supported. However, in cases in which power asymmetry interacts with LTO culture, a significant and positive relationship is observed with soft contracts $(\beta=.213, \mathrm{p} \leq .05)$. This indicated that when exchange parties with asymmetric power relationship possess LTO, they tend to rely on soft contracts. This result supports $\mathrm{H} 2$.

$\mathrm{H} 3$ argues that a positive relationship exists between power asymmetry and hard contracts. This result supports $\mathrm{H} 3(\beta=.224, \mathrm{p} \leq .05)$. The results indicate that exchange parties with high power asymmetry in the relationship with their supplier are likely to rely on hard contracts. However, the interaction effects of LTO and power asymmetry do not influence the exchange parties' adoption of hard contracts. Thus, $\mathrm{H} 4$ was not supported.

\section{DISCUSSION}

\section{Conclusion}

In this study we have evaluated one aspect of culture--time orientation--which can be quite important to international companies that establish contractual relationships with partners. Along with a host of other cultural influences, time orientation should be carefully considered when executing a contract with a partner in a different culture.

The results of this study reveal that companies with LTO cultures tend to prefer and predominantly utilize soft contracts in partner relationships. When firms anticipate that their relationships with partners will continue into the future, they are likely to develop a mutual understanding regarding expected roles and behaviors. As future contingencies are difficult to predict, exchange parties tend to develop mutually acceptable behavior standards in order to deal with future contingencies. Thus, exchange parties under a high LTO culture are generally more likely to develop soft contracts that facilitate future benefits by permitting adjustments as contingencies arise on the basis of implicit assumptions of mutual gain.

Exchange parties that evidence asymmetrical power relationships with their suppliers rely on hard contracts to some degree. This choice might be expected on the basis of their desire for some protection against opportunistic behavior. Thus, in drafting a hard contract, firms may be assumed to be motivated in a manner consistent with the culturally formed short-term time orientation.

By way of contrast, statistical analysis demonstrates that exchange parties with a high LTO culture tend to rely on soft contracts, although they enjoy a power advantage over their suppliers. Thus, even though the hard contract is an option frequently selected by exchange parties with asymmetrical power, hard contracts in and of themselves cannot provide perfect protection to the parties. Some LTO firms may have become disenchanted with this weakness of hard contracts, and have thus turned to soft contracts as an alternative.

\section{Managerial Implications}

An American manager who assumes that a hard contract with an Asian supplier affords conventional protection against opportunism may, in fact, inadvertently reduce the partnership's potential, especially if the Asian perceives all of the explicit contractual language as evidence of distrust. Likewise, a hard contract may limit the ability of the international partner companies to develop a stronger "soft" relationship over time. Thus, we recommend that international partners think carefully about time orientation, as one of several crucial cultural issues which have not traditionally received adequate attention, prior to entering into a contractual relationship in a culture which perceives time differently. Explicit recognition of this difference may facilitate the creation of a contract with specific provisions for relatively early and regular renegotiation as the relationship evolves.

Western companies that plan to operate in Asian countries and with Asian partners should be aware that the nature of the contracts upon which they rely is not "culture-neutral." Soft contracts in LTO countries evolved from cultural assumptions quite unlike the motives that guide contract choices in the West. When US companies establish manufacturing facilities in East Asia, they should both anticipate and seek to resolve time-orientation 
issues. If they desire short-term benefits in their relationships with local customers or suppliers, they may encounter difficulties owing to the mismatch of time orientation.

Asian companies may feel uncomfortable with US companies which insist on explicit contracts, which may simply be a matter of "good business" to an American manager, but could be indicative of unwillingness to establish a long-term relationship to the Asian partner. This can create misunderstandings which would jeopardize possible fruitful relationships. However, Asian companies must understand that hard contracts are a business convention in the West and that relationships initiated under such a contract may well develop into the more familiar "soft contract" relationship over time. Rather than pursuing only long-term benefits from a relationship with U.S. partners, an Asian company may also consider that a hard contract could result in both short-term benefits and potential future soft contracts.

\section{Limitations and Future Research}

We focused on one dimension of culture - namely, time orientation. Other cultural dimensions, including collectivism (Hofstede 1991), may also exert a profound influence on the success of intercultural contracts. Exchange parties in collectivist cultures will be less likely to worry about opportunistic behavior on the parts of their partners, as collectivist cultures stress cooperation among members (Wagner 1995). Exchange parties in collectivist cultures may be expected to rely on soft contracts, which are developed during the cooperative exchange relationship.

Another factor that one may consider in the study of contractual relationships is legal conventions. In the U.S., common law provides contractual parties with a range of enforceable assumptions which need not be written into a specific contract. The Statute of Frauds (a common-law-based precept) is in force in the majority of states in the US. It holds that unwritten contracts for actions to be completed within the space of a year are enforceable (with certain exceptions.) For instance, a printing order, by convention, is rendered legally complete upon the delivery of $+/-10 \%$ of the quantity specified in the order. When the contract is silent on some disputed matter, common law precedent may uphold industry conventions. In addition, the Uniform Commercial Code (law in most U.S. states) forms a set of silent articles to commercial agreements. Its specifications need not be repeated expressly within an agreement to be enforceable. Future research should consider legal conventions in the study of contractual relationship.

\section{ACKNOWLEDGEMENT}

This research was supported by Korea Sanhak Foundation 2009

\section{REFERENCES}

1. Anderson, E. and Weitz, B. (1989). "Determinants of Continuity in Conventional Industrial Channel Dyads" Marketing Science, 8(4): 310-323.

2. Antia, K. and, Frazier, G. (2001), "The Severity of Contract Enforcement in Interfirm Channel Relationship" Journal of Marketing, 65(October): 67-81.

3. Axelrod, R. (1984), The Evolution of Cooperation, New York: Basic Books.

4. Bacharach, S. B. and Lawler. E. J. (1981) "Bargaining: Power, Tactics, and outcomes" Jossey-Bass: San Francisco.

5. Barkema, H. and Vermeulen, F. (1997) "What Differences in the Cultural Backgrounds of Partners are Detrimental for International Joint Ventures?” Journal of International Business Studies, 28 (4): 845-864

6. Bello, D. C. and Gilliland, D.I. (1997), "The Effect of Output Controls, Process Controls, and Flexibility on Export Channel Performance" Journal of Marketing, 61(January): 22-38.

7. Buvik, A. and Reve, T. (2001). "Asymmetrical Deployment of Specific Assets and Contractual Safeguarding in Industrial Purchasing Relationships" Journal of Business Research, 51(2): 101-113.

8. Cadotte, E. and Stern, L. (1979) "A Process Model of Interorganizational Relations in Marketing Channels" in Research in Marketing, Vol. 2 Jagdish Sheth, ed., JAI Press: Greenwich, CT 
9. Cannon, J., Achrol, R., and Gundlach, G. (2000), "Contracts, Norms, and Plural Form Governance” Journal of the Academy of Marketing Science, 28(2): 180-194

10. Cartwright, B. C. and Schwartz, R. D. (1973), "The invocation of legal norms: an empirical investigation of Durkheim and Weber" American Sociological Review, 38: 340-354.

11. Chang, J. and Ding,C.G. (1995), “The Influence of Culture on Industrial Buying Selection Criteria in Taiwan and Mainland China" Industrial Marketing Management, 24: 277-284.

12. Chiles, T. H. and Mcmackin, J.F. (1996), "Integrating Variable Risk Preferences, Trust, and Transaction Cost Economics" Academy of Management Review, 21(1): 73-99.

13. Doney, P. M. and Cannon, J.P. (1997) "An Examination of the Nature of Trust in Buyer-Seller Relationships" Journal of Marketing, 61(April): 35-51.

14. Dore, R. (1987), Taking Japan seriously, Stanford University Press: Stanford, CA

15. Dwyer F. R. Schurr, P.H. and Oh, S.( 1987) “Developing Buyer-Seller Relationships” Journal of Marketing, 51(April): 11-27.

16. Eng, Tech-Yong (2009) "Manufacture upgrade and inter-firm relationship development: the case of electronics firms in the Pearl River Delta" Asia Pacific Business Review, 15, (4 ) 507 - 525

17. Etger, M. and Valency, A. (1983) "Determinants of the Use of Contracts in Conventional Marketing Channels" Journal of Retailing, 59(Winter): 81-92.

18. Foa, U. and Foa, E. (1974), Societal Structures of the Mind, Charles. C. Thomas: Springfield, IL

19. Ford, D., Gadde, L., Hakansson, H., Lundgren, A., Shehota, I., Turnbull, P. and Wilson, D., (1998) "Relationships and Technology" in David Ford (Ed.), Managing Business Relationships, Wiley \& Sons Ltd: England.

20. Frazier, G. L. (1983), "Interorganizational Exchange Behavior in Marketing Channels: A Broadened Perspective" Journal of Marketing, 47(Fall): 68-78.

21. Ganesan, S. (1994) "Determinants of Long-Term Orientation in Buyer-Seller Relationships" Journal of Marketing, 58(April): 1-19.

22. Gudykunst, W. B. (1988) “Culture and Intergroup Processes” in M. Bond (Ed.), The Cross-Cultural Challenge to Social Psychology, Sage Publication: California.

23. Gundlach, T. G. and Cadotte, E. R. (1993), "Exchange Interdependence and Interfirm Interaction: Research in a Simulated Channel Setting" Journal of Marketing Research, 31(November): 516-532

24. Heide, J. B. and John, G. (1992) “Do Norms Matter in Marketing Relationships?” Journal of Marketing, 56(April): 32-44.

25. Hill, C. W. (1990) "Cooperation, Opportunism, and the Invisible Hand: Implications for Transaction Cost Theory" Academy of Management Review, 15(3): 500-513.

26. Hofstede, G. (1991). Cultures and Organization: Software of the mind, McGraw-Hill London.

27. Jacobs, L. (1991). Short-Term America, Sage Publication: London.

28. Jap, S. and Shankar,G. (2000), "Control Mechanisms and the Relationship Life Cycle: Implications for Safeguarding Specific Investments and Developing Commitment” Journal of Marketing Research, 37 (May), 227-245.

29. Kale, S. H. (1986). "Dealer Perceptions of Manufacturer Power and Influence Strategy in a Developing Country" Journal of Marketing Research, 23(November): 387-393.

30. Klein, B. (2002), "The Role of Incomplete Contracts in Self-enforcing Relationship" in Eric Brousseau and Jean-Micael Glachant (Ed.) The Economics of Contracts, Cambridge University Press, England.

31. Kumar, N., Scheer, L.K., and Steenkamp, J.E.M. (1995), "The Effect of Perceived Interdependence on Dealer Attitudes" Journal of Marketing Research, 32(August): 348- 356.

32. Lawler, E. J. and Bacharach,S.B. (1987), "Comparison of Dependence and Punitive Forms of Power” Social forces, 66(2): 446-462.

33. Lusch, R. F. and Brown, J.R. (1996), "Interdependency, Contracting, and Relational Behavior in Marketing Channels" Journal of Marketing, 60(October): 19-38.

34. Mackneil, I. R. (1980), The New social Contract, Yale University: New Haven, CT.

35. Moorman, C., Zaltman, G. and Deshpande, R. (1992), "Relationship Between Providers and Users of Market Research: The Dynamics of Trust Within and Between Organizations" Journal of Marketing Research, 29(August): 314 - 328.

36. Mooij, M. D. (1997) Global Marketing and Advertising: Understanding Cultural paradox Sage Publication: London. 
37. Morgan, R. M. and Hunt, S. D. (1994), "The Commitment-Trust Theory of Relationship Marketing” Journal of Marketing, 58(July): 20-38.

38. Nakata, C. and Sivakumar, K. (1996), "National Culture and New Product Development: An Integrative Review" Journal of Marketing, 60(January): 61- 72.

39. Newman, K. L. and Nollen, S. D. (1996), "Culture and Congruence: The Fit between Management Practices and National Culture" Journal of International Business Studies, 27(4): 753-779.

40. Noordewier, T. G., John, G., and Nevin, J. R. (1990), "Performance Outcomes of Purchasing Arrangements in Industrial Buyer-Vendor Relationships" Journal of Marketing, 54(October): 108-122.

41. Ouchi, W. G. (1981), Theory Z, Avon: New York

42. Provan K. G. and Skinner, S. J. (1989) "Interorganizational Dependence and Control as Predictors of Opportunism in Dealer-Supplier Relations" Academy of management Journal, 32(1): 202-212.

43. Rokeach, M. (1973) The Nature of Human Values, The Free Press: New York.

44. Seshadri, S. and Mishra, R. (2004), Relationship Marketing and Contract Theory. Industrial Marketing Management, 33, 513-526.

45. Sheth, J. N., Gardner, D. M. and Garrett, D. E. (1988), Marketing Theory: Evolution and Evaluation, John Wiley \& Sons: New York.

46. Smith, K. G., Carroll, S. J. and Ashford, S. J. (1995), "Intra- and Interorganizational Cooperation: Toward a Research Agenda” Academy of Management Journal, 38(1): 7-23.

47. Williamson, O. (1975), Markets and hierarchies, The Free Press: New York.

48. Williamson, O. (1991), "Comparative Economic Organization: The Analysis of Discrete Structural Alternatives” Administrative Science Quarterly, 36(June): 269-296.

49. Yeh, R. S. and Lawrence, J. (1995), "Individualism and Confucian Dynamism: A Note On Hofstede's Cultural Root To Economic Growth” Journal of International Business Studies, 26(3): 655-669.

50. Yeung, I. Y. and Tung, R. L. (1996), “Achieving Business Success in Confucian Societies: The Importance of Guanxi (Connection)" Organizational Dynamics, 25(2): 54-65.

51. Polo-Redondo, Yolanda and Jesús Cambra-Fierro (2008) "Influence of the standardization of a firm's productive process on the long-term orientation of its supply relationships: An empirical study" Industrial Marketing Management, 37 (4) 407-420

52. Zhao, Yushan, and Tamer Cavusgil (2006) "The effect of supplier's market orientation on manufacturer's trust” Industrial Marketing Management, 35 (4) 405-414. 